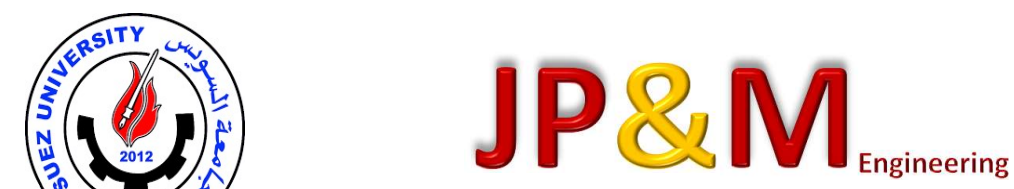

\title{
A Study on Catalyst Entrainment from Ethylene Oxychlorination Fluidized Bed Reactor
}

\author{
El-Maghraby, R. M., ${ }^{* a, b}$ Youssef, A. A. ${ }^{c}$ and Shoaib, A. M. ${ }^{a}$ \\ ${ }^{a}$ Faculty of Petroleum and Mining Engineering, Suez University, Suez, Egypt \\ bEnhanced Oil Recovery Laboratory, Suez University, Suez, Egypt \\ 'The Egyptian Petrochemicals Company, Alexandria, Egypt \\ *Corresponding author e-mail: rehab.elmaghraby@suezuniv.edu.eg
}

\section{Article Info}

Received: 21 Nov. 2020

Revised: 7 Jan. 2021

Accepted: 8 Jan. 2021

\section{Keywords}

Entrainment; $\mathrm{HCL}$ conversion; bubble diameter; fluidization; orifice diameter

\begin{abstract}
During the production of ethylene dichloride, the entrainment of catalyst particles out of the bed is considered a problematic issue that affects the conversion of the hydrogen dichloride and causes repeated unit shutdown. In this study the effect of the various operating conditions was measured; the fluidizing gas flowrate, the bed parameters, the reaction conditions, and the static design parameters such as the internal orifice diameter of the distributer. A simulation model was built using Mat Lab and Aspen Plus software. The results from both models were compared with the sample analysis data obtained from the laboratory. It was found that when the entering gas flow rate reached $2570.4 \mathrm{~m}^{3} / \mathrm{hr}$, the bubble diameter of the fluidizing gas reached maximum value, and hence, the entrainment of catalyst particles was at the lowest quantity of about $8.2 \mathrm{~kg} / \mathrm{m}^{2} . \mathrm{s}$. In addition, it was found that as the pressure drop through the orifice of the distributer decrease the entrainment of solids increase until an orifice diameter of $1 \mathrm{~cm}$ is reached, hence, the lowest rate of entrainment of catalyst particles is achieved. at such conditions the highest conversion of ethylene and $\mathrm{HCL}$ into Ethylene dichloride could be reached.
\end{abstract}

\section{Introduction}

Polyvinylchloride (PVC) is ranked as the third produced thermoplastic from the chemical industries around the world after polyethylene and polypropylene [1]. PVC is produced by polymerizing the vinyl chloride monomer (VCM) [2]. An annual growth from 6 to $8 \%$ in the world consumption of PVC is expected in the next ten years.

Nowadays, the balanced process is used for the production of a huge amount of PVC worldwide. In this process, the direct chlorination and the oxychlorination processes are combined together [3]. After this, the produced ethylene dichloride is purified, and cracked in a thermal cracker for conversion to vinyl chloride monomer. The direct chlorination reactor is operated at low pressure and temperature. The hydrochloric acid produced from the cracking reaction is consumed in the oxychlorination process in the presence of oxygen and ethylene to produce ethylene dichloride.

The base reactant of the oxychlorination [4] process is either pure oxygen or air, the use of air is due to its low cost and availability. Today's processes use pure oxygen to avoid the formation of nitrous oxide (NOx) and other nitrogen-based by-products, in addition to reducing the amount of the off gasses from the reactor, hence the cost of treating the off gases is reduced. These advantages offset the associated cost when consuming pure oxygen instead of air in the oxychlorination process.

The reaction kinetics of ethylene and cupric chloride to form ethylene dichloride was investigated by Wachi and Asai [5]. It was found that the rate equation is first order and the dependency on ethylene concentration obeys Lungmuir- Hinshellwood kinetics. Morira and Pires [6] studied oxychlorination process. Simulation was used and the effect of various operating parameters were studied. They found that bed height, residence time and emulsion temperature were the largest influencer on the reactor performance. CFD model (Computational Fluid Dynamics based on the Eulerian-Eulerian flow model) was developed by Junsittiwate, Rawinun and Anoma Kodchakong [7] to predict the effect of the different parameter on the process under study.

The orifice distributors were studied by Harrison et. al. [8]. Model was developed to study in more details the effect of entrance height and gas/solid flow above the distributor. The study found that particle size of 
catalyst, fluidized velocity, spacing between the orifices on the distributor and the flow rate of the inlet gas greatly affect the performance of the fluidized bed reactor. In addition, Ballarini et al. [9] invented an oxychlorination reaction model for the production of different species and various by-products. The study concluded that the first model was not able to reproduce the actual data obtained from the industrial scale units.

In this study, the catalyst entrainment in the oxychlorination reactor will be investigated. The effect of inlet gas velocity, orifice diameter of the distributor, bubble diameter and fraction and the temperature of the reactor will be studied. In addition, the mass of copper content in the gas from the bottom of the quencher was analysed in the laboratory to give indication on the amount of the catalyst that was entrained out of the reactor.

\section{Oxychlorination Process}

In this study, the oxychlorination reactor will be investigated. This reactor was licensed by Thyssenkrupp UHDE at the Egyptian petrochemicals company. It operates at temperature ranging from 208 to $215^{\circ} \mathrm{C}$ and at a pressure range from 2.8 to 3.2 bar. The oxychlorination reaction occurs in a fluidized bed reactor where, the ethylene is converted to ethylene dichloride in presence of cuprous chloride catalyst based on a support of gamma alumina. The reaction follows the following steps:

$\mathrm{CH}_{2}=\mathrm{CH}_{2}+2 \mathrm{CuCl}_{2} \rightarrow 2 \mathrm{CuCl}+\mathrm{ClH}_{2} \mathrm{C}-\mathrm{CH}_{2} \mathrm{Cl}$

$1 / 2 \mathrm{O}_{2}+2 \mathrm{CuCl} \rightarrow \mathrm{CuOCuCl}_{2}$

\section{$2 \mathrm{HCl}+\mathrm{CuOCuCl}_{2} \rightarrow 2 \mathrm{CuCl}_{2}+\mathrm{H}_{2} \mathrm{O}$}

The oxychlorination reactor shown in Fig.1 is a carbon steel vessel with two inlet feed streams, the $\mathrm{HCL}$ and oxygen stream that enters through a sparger directed downward, and the other feed stream is the ethylene and the recycle gas compressor discharge that enters through the distributer which is directed upward. The reactor also contains a cooling coils immersed in the fluidized bed and three cyclones for better separation efficiency.

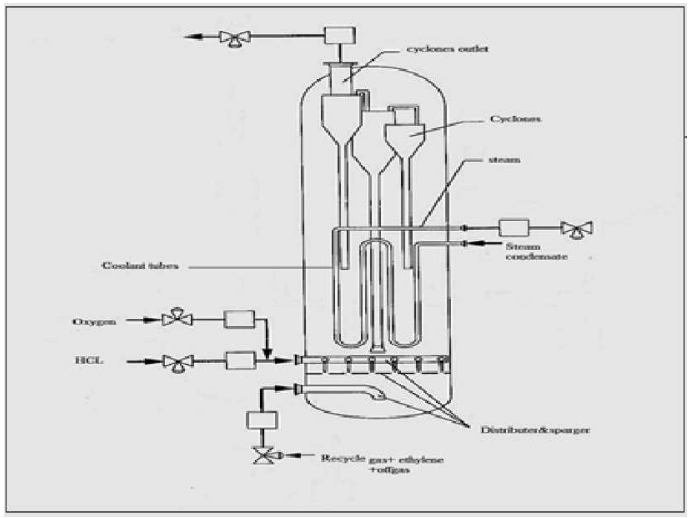

Figure 1 The oxychlorination reactor internals.

\section{Aspen plus simulation and MAT LAB Iteration}

The oxychlorination reactor was simulated using the Aspen plus program as shown in Fig. 2 The reacting gas was introduced to the fluidized reactor from the bottom, it is then allowed to flow upward as bubbles. The operating conditions were as following; the reactor temperature was $215{ }^{\circ} \mathrm{C}$, fluidization gas flow rate was $2650 \mathrm{~m}^{3} / \mathrm{hr}$., the bed height was $11 \mathrm{~m}$ and the bed diameter was $2.78 \mathrm{~m}$. In addition, MAT LAB was used to study the relation between the reacting gas bubbles volume fraction and its velocity, the rising bubble velocity, the gas bubbles diameter, and the effect of the variation in the superficial gas velocity, orifice diameter and reactor temperature on the entrained solids. The governing equations is included in the Supporting Data File.

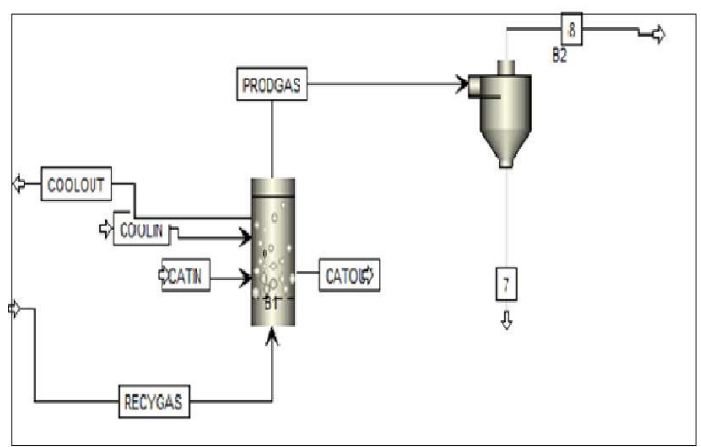

Figure 2 The oxychlorination fluidized bed reactor simulated using Aspen plus.

\section{Results and Discussion}

MAT LAB and Aspen Plus simulation were used to study the oxychlorination reactor, results were obtained as following;

\section{Relation between reacting gas bubbles volume fraction and its velocity.}

According to Fig. 3 as the entering gas velocity increases, the volume fraction of bubbles increases up to a certain value of gas velocity of $725,000 \mathrm{~cm} / \mathrm{s}$. After which it remains constant for a while with the increase in gas velocity, then at a value of 740,000 $\mathrm{cm} / \mathrm{s}$ the volume fraction of bubbles increases rapidly. This indicates that the catalyst particles begin to leave the reactor bed.

\section{Effect of entering gas velocity on rising bubble velocity}

According to Fig.4 as the entering gas velocity increases, the rising bubble velocity increases to a certain value, afP a g e | 13ter which it decreases at a slight rate, for a range of entering gas velocity between $720,000 \mathrm{~cm} / \mathrm{s}$ and $740,000 \mathrm{~cm} / \mathrm{s}$, then the rising bubble velocity starts to increase again. 


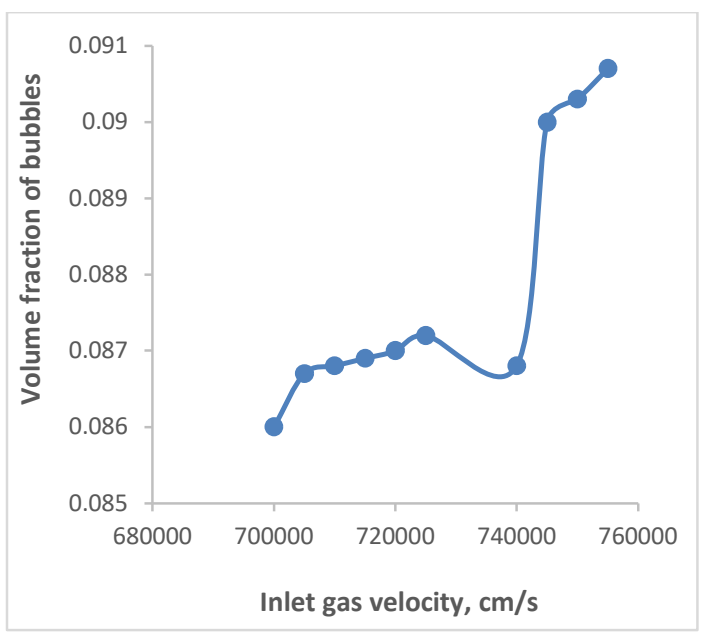

Figure 3 The effect of entering gas velocity on the volume fraction of bubbles.

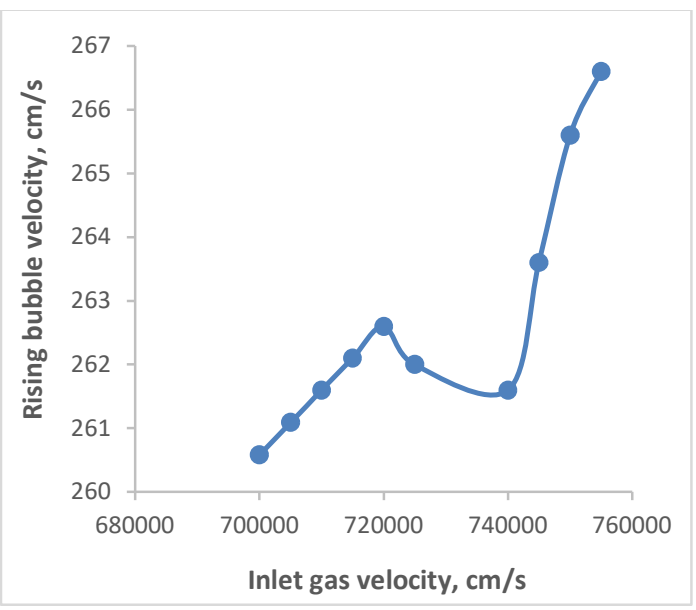

Figure 4 The effect of the entering gas velocity on the rising bubble velocity.

\section{Relation between bubble diameter and superficial gas velocity}

The gas bubble diameter increases with the increase in the superficial gas velocity, see Fig. 5 The maximum bubble diameter will be at the terminal velocity of the gases moving through the bed.

\section{Effect of superficial gas velocity on entrainment}

As shown in Fig. 6 a and b, the velocity of the gas is directly proportional to the amount of the solids that entrained out of the bed. As the gas velocity reaches a value higher than $2570 \mathrm{~m}^{3} / \mathrm{hr}$, the mass of entrained solids out of the bed increases significantly. This means that the mass of catalyst available in the oxychlorination reactor decreases and as a result the gas conversion decreases. However, at gas velocity lower than $2570 \mathrm{~m}^{3} / \mathrm{hr}$. the entrained mass of solids will be at its minimum as calculated from the MAT $L A B /$ Aspen Plus, which reflects the lowest quantity of entrained catalyst that could achieve optimum conditions of the fluidized bed.

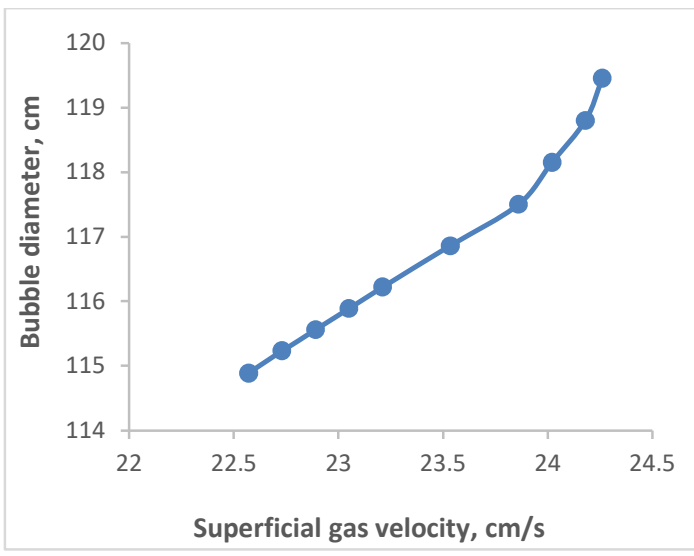

Figure 5 The relation between superficial gas velocity and the bubble diameter.

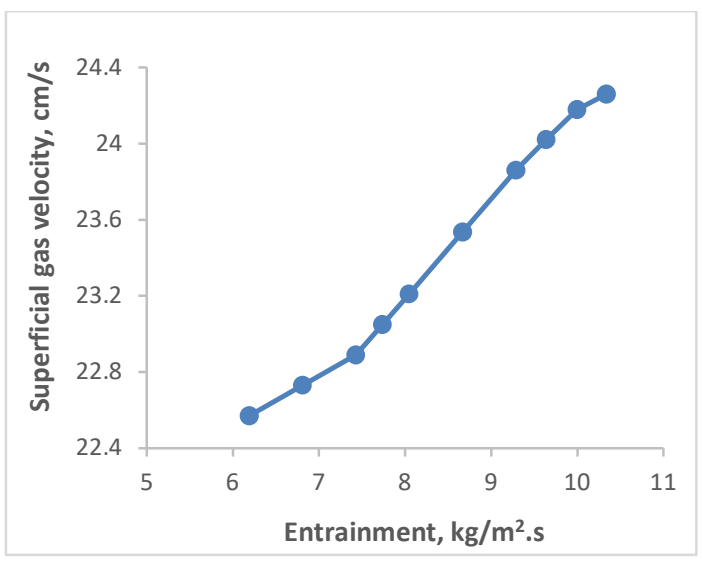

Figure 6-a Relation between the superficial inlet gas velocity and mass.

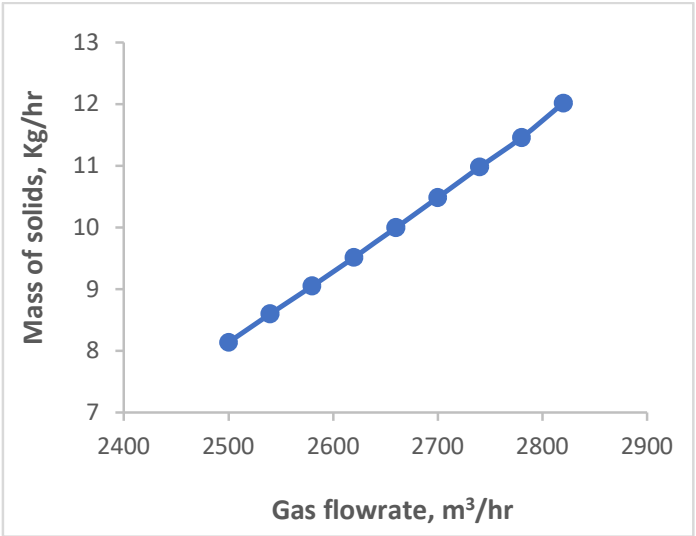

Figure 6-b Relation between gas flowrate and mass of entrained solids out of the bed.

\section{The effect of gas flowrate on the concentration of cupper in the quencher bottom}

Actual data from the oxychlorination reactor was recorded for 6 months. The quencher bottom output was analysed versus the recycle gas flowrate, as shown in Fig.7. It was found that the amount of copper decreases with the decrease in the recycle gas flowrate. Keeping in mind that the low content of 
copper is a direct indication of the mass of catalyst coming out with the gas from the reactor. In addition, low copper content means lower chance for a complex to be formed with the carbonate and bicarbonate salts, hence lower possibility for quencher bottom blockage to occur.

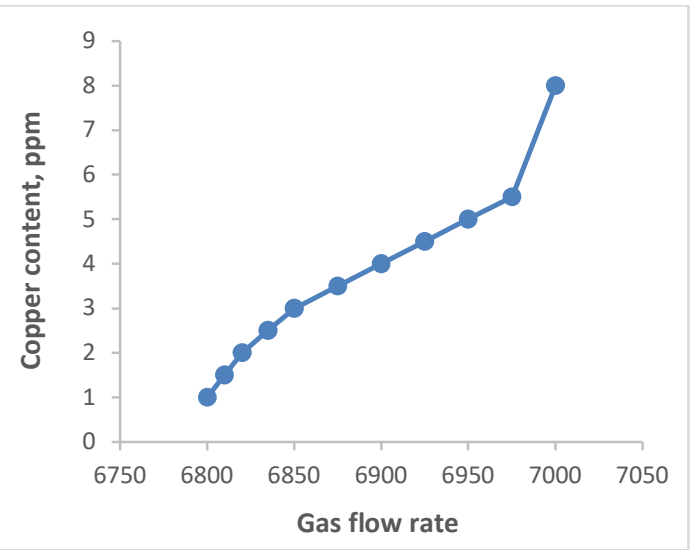

Figure 7 The effect of gas flowrate on the concentration of cupper from the bottom of the quencher.

\section{Effect of orifice diameter and temperature variation on the mass of entrained solids}

According to Fig. 8 and 9, at constant gas flowrate of $2570 \mathrm{~m}^{3} / \mathrm{hr}$. the mass of the entrained catalyst out of the fluidized bed decreases with the increase in the orifice diameter of the distributer and with the decrease in bed temperature.

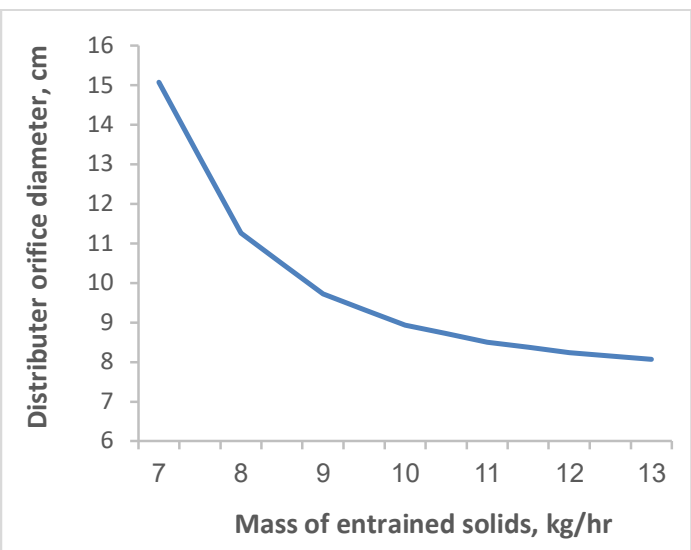

Figure 8 The effect of distributor orifice diameter variation on the mass of entrained catalyst.

\section{Comparison with laboratory data}

In this section, the results obtained from Aspen Plus model such as bed temperature and its relation with mass of entrained catalyst is compared with the actual data from the industrial reactor. Output from the industrial reactor was recorded and the concentration of the copper in the quencher bottom was analyzed and compared with the bed temperature as shown in Table 1. It is clear that, data agrees, as both the copper content and the mass of entrained catalyst increases with the increase in bed temperature.

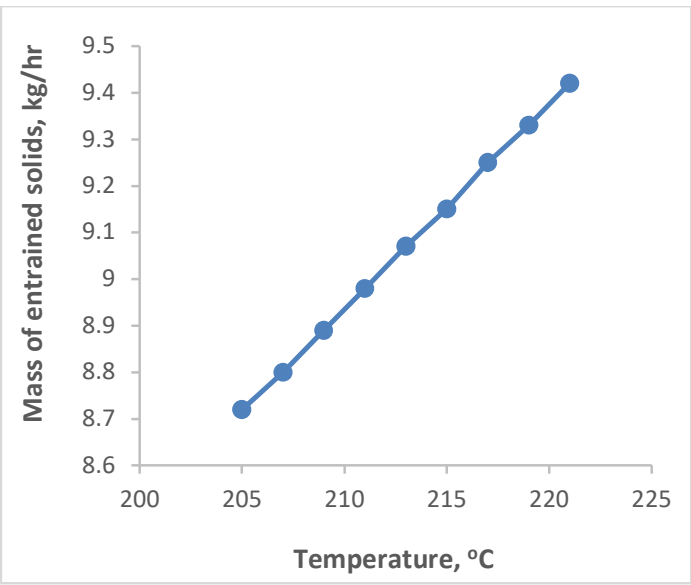

Figure 9 Relation between bed temperature and mass of entrained solids.

Table 1 Comparison between aspen plus reactor model and the industrial reactor.

\begin{tabular}{|l|c|c|c|c|c|c|}
\hline $\mathbf{T}^{\circ} \mathbf{C}$ & 207 & 208 & 209 & 210 & 211 & 212 \\
\hline $\begin{array}{l}\text { Cupper content, } \\
\text { ppm }\end{array}$ & 1 & 2 & 3 & 4 & 5 & 8 \\
\hline Mass, kg & 8.72 & 8.8 & 8.89 & 8.98 & 9.07 & 9.15 \\
\hline
\end{tabular}

\section{Conclusion}

In this study, Aspen plus and MAT Lab was used to model ethylene dichloride production in the oxychlorination fluidized bed reactor. The copper content in the exiting gas was analyzed in the laboratory, and the simulation data was compared with the industrial data, it was found that both data agree. In addition, it was found that the bubble diameter of the inlet gas increases with the increase in the superficial gas velocity. Moreover, increasing the entering gas velocity increases the rate of solids entrainment out of the bed. The copper content at the quencher bottom increases by increasing the entering gas flowrate above $2570 \mathrm{~m}^{3} / \mathrm{hr}$. It is recommended that the fluidizing gas flowrate will be decreased to lower than $2570 \mathrm{~m}^{3} / \mathrm{hr}$. in order to minimize the solids entrainment to the lowest possible value.

\section{Funding sources}

This work was supported by the Enhanced Oil Recovery Lab, Suez University, Egypt and STDF (Science and Technology Development Fund) [Project ID 12395].

\section{Conflicts of interest}

"There are no conflicts to declare".

\section{Acknowledgements}

This work was supported by the Enhanced Oil Recovery Lab, Suez University, Egypt and STDF (Science and Technology Development Fund) [Project ID 12395]. 


\section{References}

[1] Maddah, Hisham A. Polypropylene as a promising plastic: A review, Am. J. Polym. Sci 6.1 (2016): 1-11.

[2] Magistro, A. J. Cowfer, J. A. Real world of industrial chemistry, Oxychlorination of ethylene. J. Chem. Educ. 1986: 63-1056.

[3] Lamberti, C. Prestipino, C. Bonino, F. Capello, L. Bordiga, S. Spoto, G. Zecchina, A.; Diaz Moreno, S. Cremaschi, B. Garilli, M. Marsella, A. Carmello, D. Vidotto, S. Leofanti, G. The Chemistry of the Oxychlorination Catalyst, Chem., Int. Ed. 2002, 41-2341.

[4] Gel'perin, E. I.Bakshi, Y. M..Zyskin, A. G.; Snagovskii, Y. S. Avetisov, A. K. Kinetics and Mechanism of Ethylene Oxychlorination. Russian Chemical Industry 1996, 28-38.

[5] Wachi, Shun, and YousukeAsai. Kinetics of 1, 2dichloroethane formation from ethylene and cupric chloride, Industrial \& engineering chemistry research 33.2 (1994): 259-264.
[6] Moreira, J. C. S., and C. A. M. Pires. Modelling and simulation of an oxychlorination reactor in a fluidized bed. The Canadian Journal of Chemical Engineering 88.3 (2010): 350-358.

[7] Junsittiwate, Rawinun, Anoma Kodchakong, and Thongchai Rohitatisha Srinophakun. Ethylene Dichloride Production by Oxychlorination in a Fluidized Bed Reactor with CFD Model. Asian Journal of Applied Sciences 6.5 (2018).

[8] Collins, R., De Moraes, F. F., Davidson, J. F., \& Harrison, D. (1978). The motion of a large gas bubble rising through liquid flowing in a tube.Journal of Fluid Mechanics, 89(3), 497-514.

[9] Montebelli, A., Tronconi, E., Orsenigo, C., \& Ballarini, N. (2015). Kinetic and modeling study of the ethylene oxychlorination to 1 , 2-dichloroethane in fluidized-bed reactors. Industrial \& Engineering Chemistry Research, 54(39), 9513-9524. 